\title{
ACTIVE INFRARED TESTING OF COMPOSITES USING 3D COMPUTER SIMULATION
}

\author{
Anatoliy Protasov ${ }^{1 *}$ \\ ${ }^{1}$ Department of Non-Destructive Testing Devices and Systems, National Technical University of \\ Ukraine "Igor Sikorsky Kyiv Polytechnic Institute", Av. Peremohy 37, Kyiv, 03056, Ukraine
}

(Received: May 2017 / Revised: January 2018 / Accepted: January 2018)

\begin{abstract}
Composite sandwich constructions are very widely employed in the modern aircraft industry, honeycomb panels among them. The principal defects of honeycomb sandwiches are cover detachment because of cell collapse or poor adhesive, which can lead to water penetration in cells. Recently, the thermal method of non-destructive testing (infrared thermography) has begun to be applied to the diagnostics of honeycomb constructions, and has some advantages over traditional methods. However, thermal processes are transient, and this complicates the selection of optimal parameters for monitoring. The purpose of this work is to investigate the possibilities of the thermal method for honeycomb panel inspection using computer simulation. The COMSOL Multiphysics package was used for the simulations. A 3D model of the honeycomb panel was proposed, and two possible defects considered: the detachment of the panel cover from the filler and the presence of water in the defective cell. The implementation of the proposed 3D model made it possible to investigate the effect of a defect on the thermal field of the panel surface. The simulation results showed that optimal testing time is significantly different for various types of panels. The correct selection of testing parameters increases the accuracy of the testing procedure. The results of experimental investigation confirmed the adequacy of the proposed model for thermal testing.
\end{abstract}

Keywords: Composite materials; Computer simulation; Infrared testing; Three-dimensional model

\section{INTRODUCTION}

Multi-layer composite materials are widely used in modern aircraft construction. They are characterized by high strength and low specific gravity (Ibarra-Castanedo et al., 2007). In aircrafts of the latest generation, more than $30 \%$ of the fuselage, wing, keel and other parts of the aircraft are made of honeycomb panels (Vavilov \& Nesteruk, 2005).

The principal defects of honeycomb sandwiches are the detachment of the cover from the filler due to the non-gluing or crushing of the cells. These defects can arise both during the operation of the aircraft and during the manufacture of honeycomb sandwiches, because of process violation. The most dangerous defect is the ingress of water into the cellular structures of the airplane elements (Meng, 2008; Oliveira et al., 2011). At low temperatures, water freezes and increases its volume, which leads to the destruction of honeycomb cells and significantly reduces the strength of the entire panel design. The traditional methods of defect detection in

*Corresponding author's email: a.g.protasov@gmail.com, Tel: +38-044-204-95-47, Fax: +38-044-204-85-01 Permalink/DOI: https://doi.org/10.14716/ijtech.v9i3.218 
composite materials include ultrasonic non-destructive testing. However, this has a low productivity and needs contact. The less common method in aviation is the X-ray method. Its application is limited due to its cumbersome technique and safety risks for personnel.

Recently, the active thermal method of testing (active thermography) has begun to be applied to the diagnostics of composite materials, as it allows users to identify any defect in the material structure (Galietti \& Palumbo, 2016) and has certain advantages over traditional methods. It is non-contact, allows the exploration of large areas in a relatively short time, and poses no risk to the safety of personnel (Sánchez-Carballido et al., 2014; Yu et al., 2014). Thermographic techniques use an external heat source to excite thermal waves in the material. The presence of a defect causes various thermophysical local properties of the material, which leads to abnormal temperatures on the material surface. The ability of thermography to detect defects in honeycomb panels has been demonstrated in various works. The use of pulse thermography to detect the penetration of water into composite honeycomb panels was investigated by Meng (2008), Oliveira et al. (2011), and Xingwang and Feifei (2012). Zhao et al. (2011) researched pulse thermography to detect not only water but also hydraulic oil in sandwich panels. The quantitative estimation of water content in aircraft honeycomb panels using transient infrared thermography was carried out by Vavilov and Nesteruk (2005).

The active infrared testing method is successfully applied to the inspection of the condition of aircraft structural elements in companies such as Airbus Industry, Inc. and Boeing. Although this method of testing has begun to be applied in industry, the received results of the research are insufficient for its full and wide application. The influence of material structure parameters and heating parameters on the detection effect has not been studied completely. In addition, there are some problems connected to flaw detection in honeycomb structures made of aluminum alloys and composites. Aluminum constructions have high thermal conductivity, which provides transience of all heat processes; this impedes the testing procedure. Composite structures retain high temperatures for a long time. This enables the tester to obtain a more precise result. Thus, different honeycomb structures need to be inspected using different modes of testing.

The purpose of this work is to investigate the possibilities of the thermal method for honeycomb panel inspection using 3D computer simulation, which will allow us to visualize processes that are invisible to the researcher.

\section{METHODOLOGY}

Computer simulation is widely used for investigation of thermal processes in infrared thermography (Laaidi \& Belattar, 2012; El Amiri et al., 2014). The application of computer simulation to the direct problem of thermal testing in 2D was considered in Protasov (2009). The solution of the direct problem of thermal testing for honeycomb panels is considered using the example of a three-dimensional model. To implement the proposed method, we used the COMSOL Multiphysics application package.

\subsection{Simulation}

As a model, we constructed a honeycomb structure that has two types of defects: detachment of the cover from the honeycomb filler and the presence of water in the honeycomb cell. The upper cover of the honeycomb panel is heated with an external heat source. The thermal processes occurring in the sample model are described by the three-dimensional non-stationary heat equation: 


$$
c_{n} \rho_{n} \frac{\partial T}{\partial t}=\lambda_{n}\left(\frac{\partial^{2} T}{\partial x^{2}}+\frac{\partial^{2} T}{\partial y^{2}}+\frac{\partial^{2} T}{\partial z^{2}}\right)
$$

where $T$ is temperature, $t$ is current time, and $x, y, z$ are the triaxial coordinates of analyzed points in the $n$th area.

$$
(x, y, z) \in \sum_{n=1}^{3} M_{n} ; c_{n}, \rho_{n}, \lambda_{n} ;
$$

where $c_{n}, \rho_{n}, \lambda_{n}$ denote thermal capacity, density, and coefficient of thermal conductivity in the $n$th area, $n=1$ corresponds to the material of the honeycomb panel, $n=2$ corresponds to the air-type defect, and $n=3$ corresponds to water inside of the honeycomb filler. There are three areas in the model, which have different thermophysical properties. $M_{1}$ is the area of the honeycomb structure (aluminum), $M_{2}$ the area of the air-type defect (cover detachment), and $M_{3}$ the area filled with water (Figure 1).

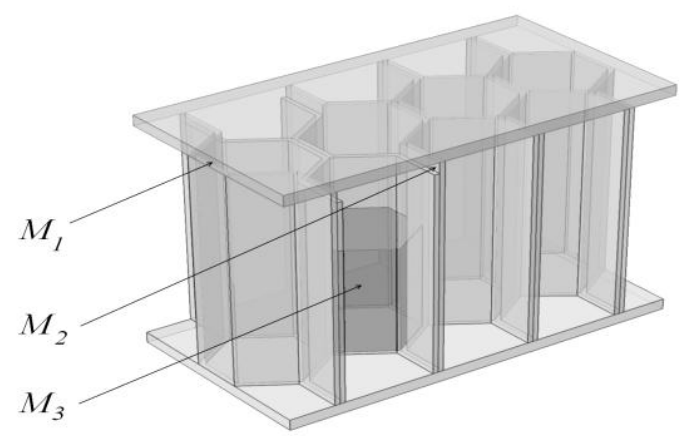

Figure 1 General view of the three-dimensional model of a honeycomb panel

There is a thermal equilibrium condition at the boundaries of areas $M_{1}$ and $M_{2}$, and areas $M_{1}$ and $M_{3}$, i.e. boundary conditions of the fourth type. The top surface of the honeycomb panel is heated with an external source. The remaining outer surfaces of the panel participate in the process of heat exchange with the environment according to Newton's law, which corresponds to boundary conditions of the third type. The initial conditions can be specified as follows: $\left.T\right|_{t=0}=T_{0}$.

The distance between the upper and bottom covers of a honeycomb panel is $15 \mathrm{~mm}$, the cover thickness is $1 \mathrm{~mm}$, and the thickness of the aluminum foil filler is $0.2 \mathrm{~m}$. The values of the variables that were used during the simulation are in Table 1. 
Table 1 The values of the variables

\begin{tabular}{lccc}
\hline Material & $\begin{array}{c}\text { Thermal capacity }(c) \\
\times 10^{-3}(\mathrm{~J} / \mathrm{kg} . \mathrm{K})\end{array}$ & $\begin{array}{c}\text { Density }(\rho) \\
\times 10^{-3}\left(\mathrm{~kg} / \mathrm{m}^{3}\right)\end{array}$ & $\begin{array}{c}\text { Thermal conductivity }(\lambda) \\
(\mathrm{W} / \mathrm{m} . \mathrm{K})\end{array}$ \\
\hline Carbon fiber & 0.85 & 1.5 & 0.63 \\
Air & 1.006 & 1.29 & 0.0257 \\
Water & 4.19 & 0.99 & 0.64 \\
Aluminum & 0.88 & 2.7 & 209.3 \\
\hline
\end{tabular}

\subsection{Verification}

Experimental research was conducted to verify the adequacy of the proposed testing model. A honeycomb panel with composite covers and aluminum filler was used as a sample. The panel had an artificial flaw. One cell was separated from the upper cover and was filled with water. The panel thickness was $15 \mathrm{~mm}$. The upper and bottom covers were made of pressed carbon fiber with a thickness of $1 \mathrm{~mm}$. The thickness of the aluminum foil filler was $0.2 \mathrm{~mm}$.

The upper surface of the panel was heated by a halogen lamp to a temperature of $313 \mathrm{~K}\left(40^{\circ} \mathrm{C}\right)$, and then to $333 \mathrm{~K}\left(60^{\circ} \mathrm{C}\right)$. During the heating process, the temperature was measured on the top and bottom surfaces of the panel.

\section{RESULTS AND DISCUSSION}

\subsection{Simulation}

The three-dimensional model of the panel was heated to a temperature of $373 \mathrm{~K}\left(100^{\circ} \mathrm{C}\right)$. During heating, the family of thermograms of the panel's upper and bottom surfaces were obtained with a time step of 0.1 second.

Figure 2 shows (a) the thermogram of the upper surface of a defective aluminum panel; and (b) the series of thermo-contours taken at the middle line of the upper surface. A defect was considered to be the detachment of the upper cover from one cell of the panel filler $(0.4 \mathrm{~mm})$ and water presence in the same cell. The water reached a height of $7 \mathrm{~mm}$ in the cell.

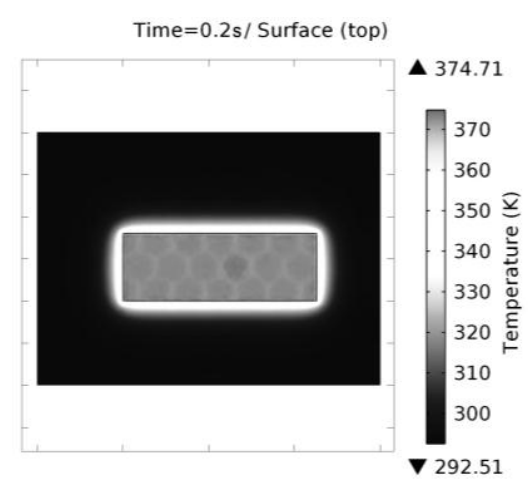

(a)

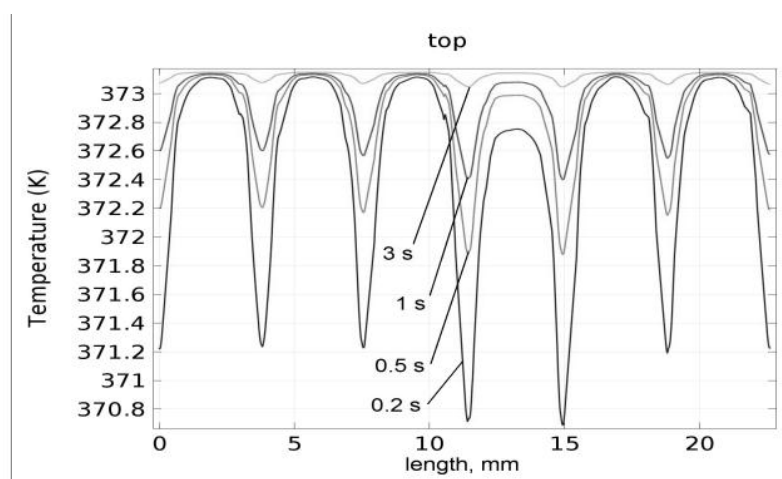

(b)

Figure 2 (a) Thermogram of the upper surface of a defective aluminum panel; and (b) the family of thermo-contours

The thermogram was obtained 0.2 seconds after the heating of the upper surface of the panel began. The thermogram cannot determine the presence of a defect in the structure (Figure $2 \mathrm{a}$ ), but the family of thermal contours on the surface of the panel can. As can be seen in Figure $2 b$, the temperature distortions in the defective cell region already appear after 0.2 seconds, and after 1 second, they practically disappear. Figure 3 shows (a) the thermogram of the bottom surface; and (b) the family of thermo-contours obtained on the midline of the bottom surface. 
As can be seen in Figure 3a, on the thermogram of the bottom surface of the panel, the distortion of the temperature field caused by the presence of defects is clearly visible. The family of thermal contours on the surface of this panel also demonstrates the presence of defects in the structure. Figure $3 \mathrm{~b}$ shows the temperature distribution on the bottom surface of the panel at different times. The maximum temperature difference between defective and defect-free cells appears 0.5 seconds after the start of heating and lasts only a few tenths of a second.

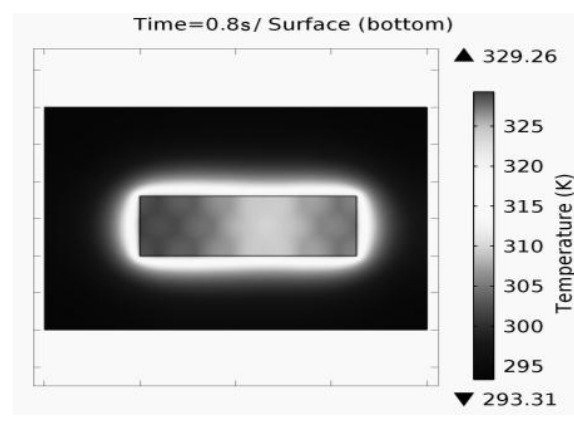

(a)

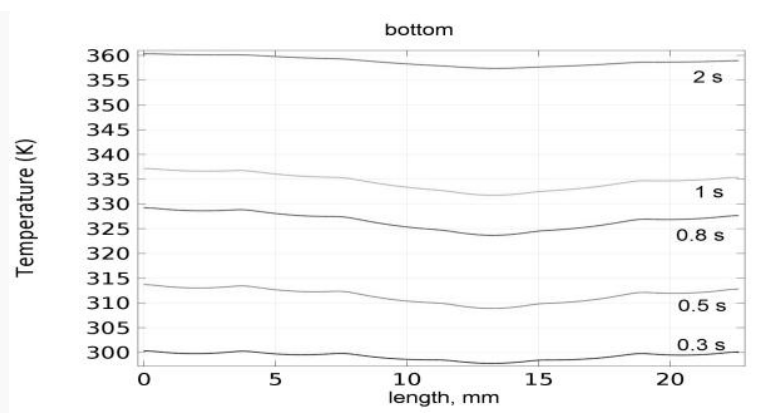

(b)

Figure 3 (a) Thermogram of the bottom surface of a defective aluminum panel and (b) the series of thermo-contours

For comparison, the simulation was repeated with a honeycomb panel made of composite materials. Figure 4a shows the temperature distribution on the upper surface of the panel. After 4 seconds of heating, the non-uniformity of the surface thermal field is observed due to the presence of a defect. Figure $4 \mathrm{~b}$ demonstrates the distortion of the thermo-profile over the defective cell filled with water. In this case, the temperature anomalies caused by the defect lasted more than 20 seconds. The maximum temperature difference was observed for 4 seconds.

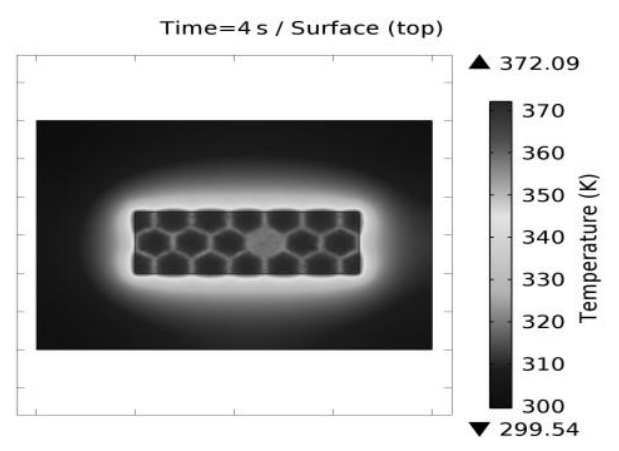

(a)

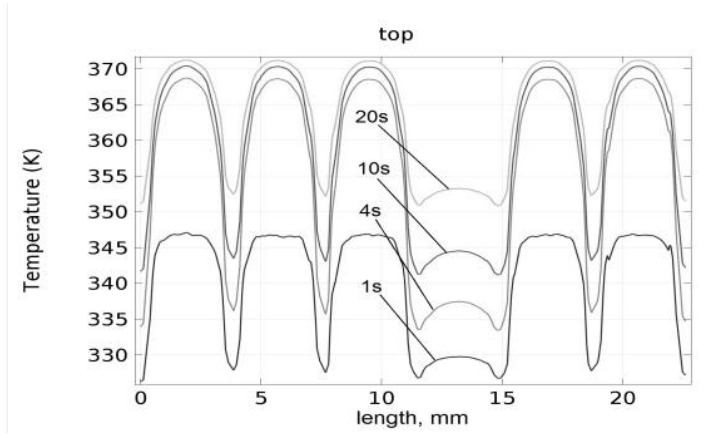

(b)

Figure 4 (a) Thermogram of the upper surface of a defective composite panel; and (b) the series of thermo-contours

Figure 5 shows the thermogram of the bottom surface of the panel and the family of thermocontours at different times. Temperature anomalies are clearly visible over a defective cell (Figure 5a). As can be seen in Figure 5b, the temperature distortions on the bottom surface of the defective composite panel begin to appear after five seconds.

Computer implementation of the proposed model of active thermography permits the researcher to obtain thermograms of honeycomb panel covers and time-dependent thermo-contours of the surface. Temperature distortions on the upper surface of a defective aluminum panel last a few tenths of a second only. The maximum temperature difference between defective and defectfree regions is $0.4 \mathrm{~K}$; after 1 second, this temperature difference disappears (Figure 2). 
Temperature distortions on the bottom surface are more pronounced. The maximum temperature difference $(4 \mathrm{~K})$ has been reached 0.8 seconds after the start of heating (Figure 3 ).

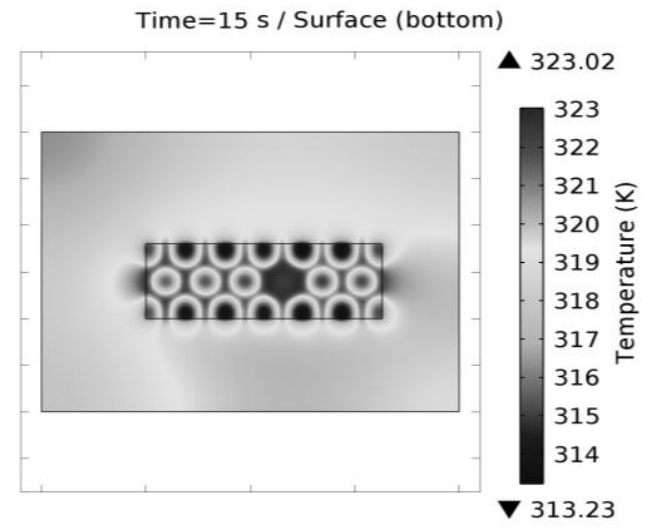

(a)

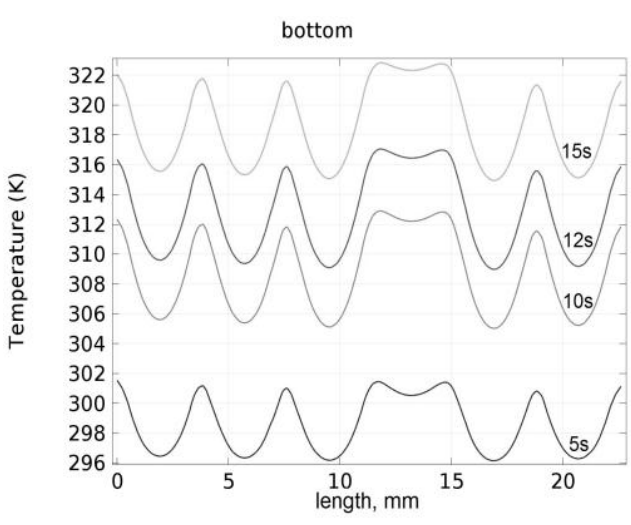

(b)

Figure 5 (a) Thermogram of the bottom surface of a defective composite panel; and (b) the series of thermo-contours

The testing parameters for a composite panel differ significantly from those for a metal panel. Thus, temperature distortion on the upper surface of the composite honeycomb panel is a few tenths of a degree, begins to manifest clearly after 4 seconds, and lasts more than 15 seconds (Figure 4).

Temperature distortions on the bottom surface of a defective composite panel begin to manifest much later (5-15 seconds) than in the metallic (0.5-2 seconds). The temperature difference is of nearly 6 degrees (Figure 5) and lasts more than 10 seconds. The obtained data indicate that the application of the thermal method to inspect honeycomb panels made of aluminum alloys may be associated with certain technical difficulties. It is very difficult to measure a slight fall in temperature within 1 second with a given accuracy.

It may be interesting for researchers of the possibilities of active thermography to know the change in temperature over time at particular points on the surface of the honeycomb panel. To simulate the heating process, 3 test points were chosen on the surface of the composite panel (Figure 6). We considered the honeycomb filler to be made of aluminum foil.

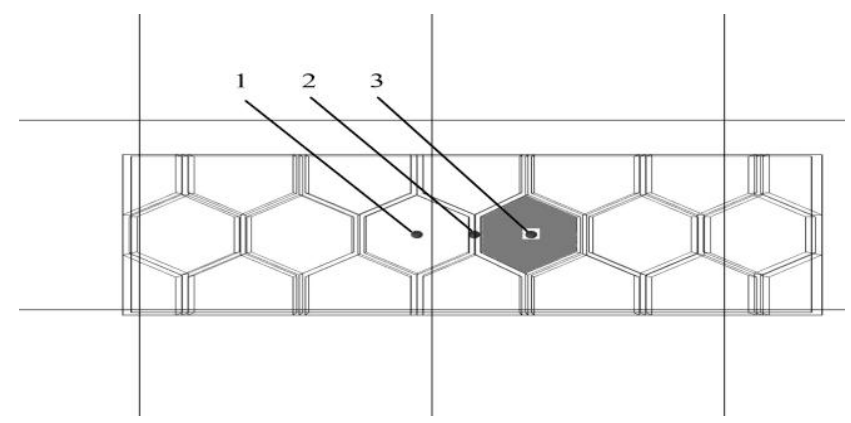

Figure 6 Layout of testing points on the surface of the honeycomb panel

Point 1 is in the center of the cell and this means there is air under the panel cover. Point 2 is above the edge of the honeycomb core. Point 3 is in the center of the defective cell (detached cover), which is filled with water. Figure 7 shows the results of heating the indicated points on the top surface of the panel. 


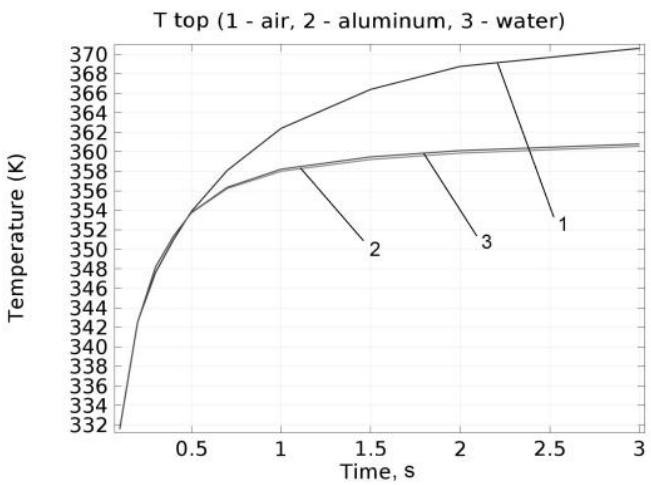

(a)

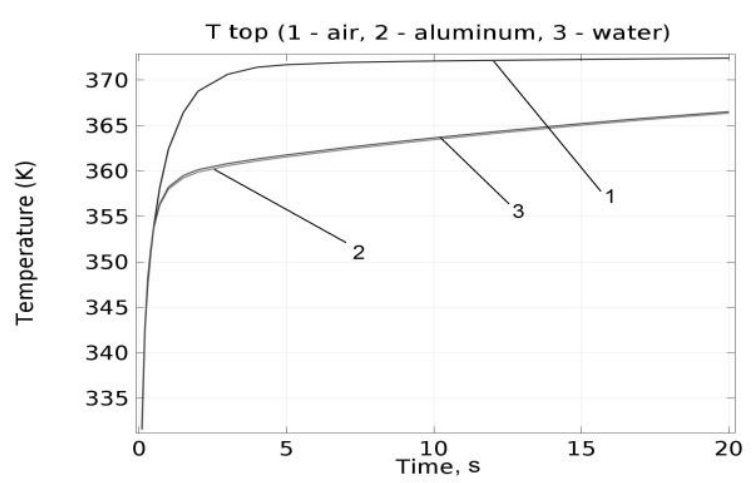

(b)

Figure 7 Graphs of temperature changes at testing points of the upper surface of the panel in two time intervals

Figure 7 shows that the temperature of point 1 is higher than that of points 2 and 3 . The maximum temperature difference appears at 5 seconds and is of about $10 \mathrm{~K}$. The processes of temperature change at points 2 and 3 almost coincide, due to the high thermal conductivity of aluminum foil and water.

Figure 8 shows the results of changing the panel temperature at similar points on the bottom surface. Figure 8 a shows that in the first seconds the heating processes of these points differ. The heating of point 1 is slower, due to the low thermal conductivity of air. Point 2 is under the cell edge and heats up faster than point 3, which is under the center of the cell with water. Further, after approximately 5 seconds, the heating curves of points 2 and 3 begin to converge (Figure 8b). The temperature difference between points 1 and 3 increases, to reach a maximum of about 5-6 K at 16 seconds. After this, the difference begins to decrease. These simulation results show the possibility of testing panels from both the heating side and the opposite side.

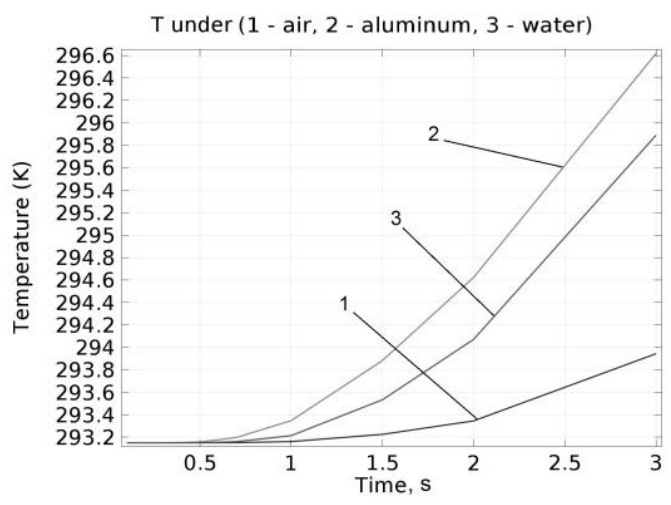

(a)

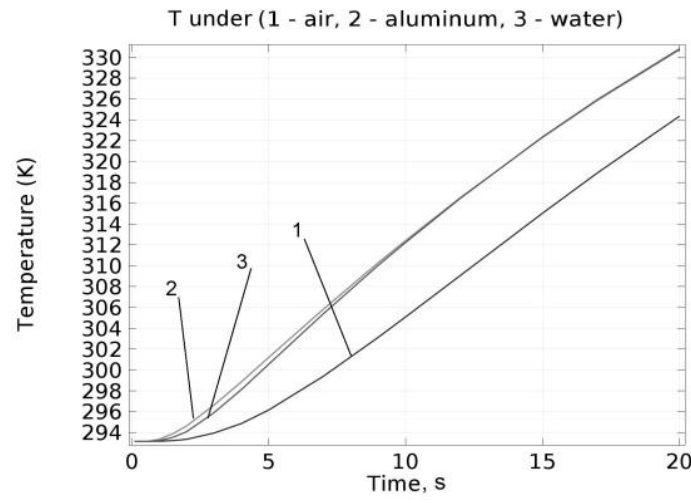

(b)

Figure 8 Graphs of temperature changes at testing points of the bottom surface of the panel in two time intervals

Computer simulation permits the investigation of thermal processes taking place in the defective panel directly during its heating. Such results are practically impossible to obtain experimentally, since the panel's temperature is measured after the end of the heating. In most cases, impulse heating is used for active thermography, and we are, in practice, observing the process of object cooling, rather than heating (Balageas, 2012; Xingwang \& Feifei, 2012; Zhao et al., 2011). The obtained results allow the researcher to define the time of occurrence of the 
maximum temperature difference between the defective and defect-free sections for each specified panel. This is the optimal time for inspection.

\subsection{Verification}

During the experiment, digital thermometers from DALLAS Semiconductor Corporation DS18S20 series were used to measure the temperature of the surface panel. Thermometers provide real-time temperature measurement in the range of $-55^{\circ} \mathrm{C}$ to $125^{\circ} \mathrm{C}$ with a resolution of $0.5^{\circ} \mathrm{C}$. They use iButton technology and connect to a 1 -Wire network. Five thermometers were used for the experiment. Two thermometers were located on the upper surface of the panel to control its temperature, and two on the bottom panel. Of the latter, one was located under the defective cell and the other under the defect-free cell. The fifth sensor was used to monitor the ambient temperature. The sensors were connected to the PC through the interface. The measurement results were displayed on the computer screen. Figure 9 shows the experimental setup with a sample.

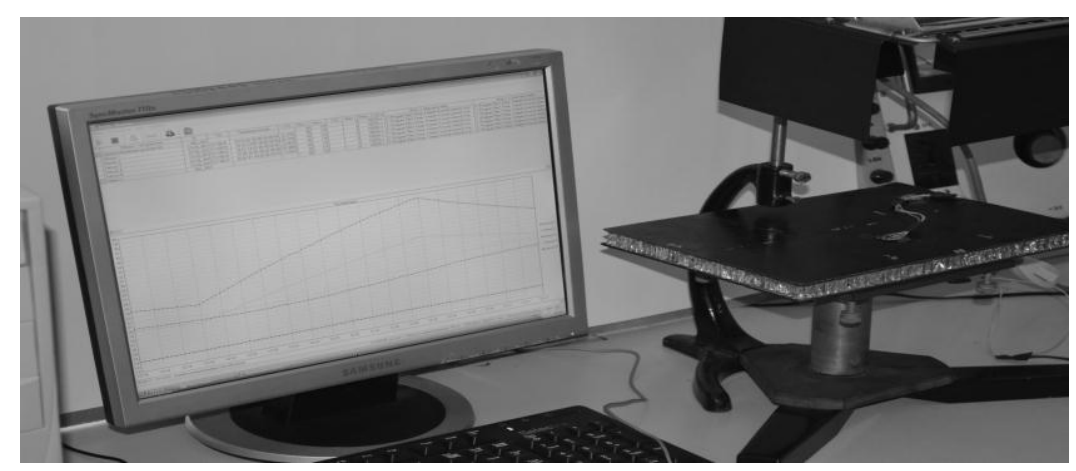

Figure 9 Experimental set up and the testing sample

The time variation of the temperature difference at the reference points on the bottom surface is shown in Figure 10. The solid curve corresponds to the simulation results, and the dashed curve reflects the experimental results. As can be seen from Figure 10, the curves are similar. Figure 10 shows the best testing time for a composite panel at different heating temperatures. The appearance of the maximum temperature difference between the defective and defect-free areas on the underside of the panel is observed after 12-13 seconds after the heating began. At a heating temperature of $313 \mathrm{~K}$, this difference was only $1.6 \mathrm{~K}$, and at a temperature of $333 \mathrm{~K}$ it was about $3.2 \mathrm{~K}$. Thus, the implementation of the proposed 3D model for computer simulation allows us to pre-determine the necessary testing parameters.

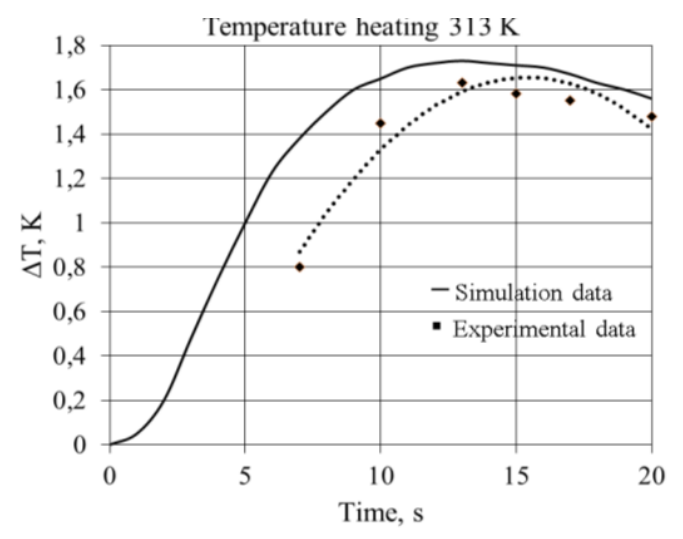

(a)

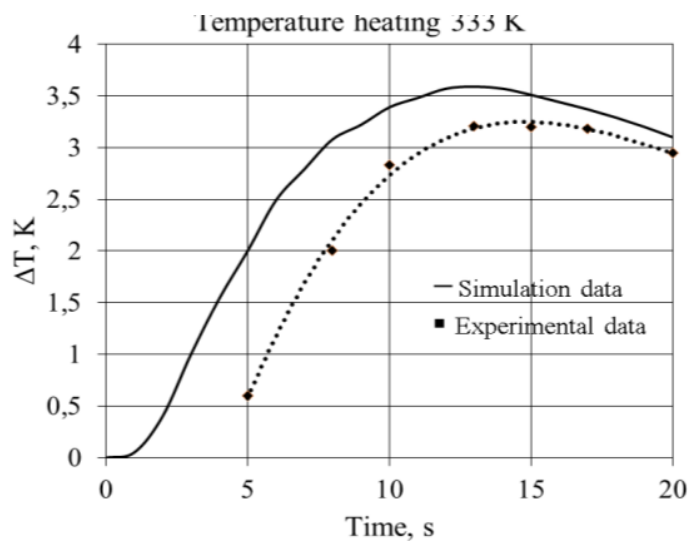

(b)

Figure 10 Temperature difference between testing points on the bottom surface, with: (a) heating temperature of $313 \mathrm{~K}$; and (b) heating temperature of $333 \mathrm{~K}$ 
The discrepancies between experimental measurements and simulation results are due to a number of reasons. The first is difference between the parameters of the sample and the model, the second is the error in measuring temperature by the contact method, and the third is uneven temperature distribution in the heating spot. However, both curves have the same tendency to change the temperature difference in time, which is very important and confirms the adequacy of the proposed model.

\section{CONCLUSION}

The obtained results confirm the possible applicability of the COMSOL Multiphysics package to study the processes that occur under active thermal testing of honeycomb panels. Honeycomb panels are of a complex composite material, the constituent parts of which have different thermophysical properties, which significantly affects the parameters of thermal testing. The implementation of the proposed 3D model for computer simulation makes it possible to investigate the thermal processes that occur inside the object during testing, which cannot be determined experimentally. This makes it possible to preliminarily determine the necessary testing parameters, namely, the optimum monitoring time and the heating temperature for each specific case. This improves the accuracy of monitoring the honeycomb panels. The results of experimental studies confirm the adequacy of the proposed model of thermal testing.

\section{REFERENCES}

Balageas, D.L., 2012. Defense and Illustration of Time Resolved Pulsed Thermography for NDE. Journal of Quantitative Infrared Thermography, Volume 9(1), pp. 3-32

El Amiri, A., Beattar, S., Sahnoun, S., 2014. The Numerical Modeling and the Infrared Thermography Applied to the Detection of Fluids Nature in Pipes. In: Proceedings of the $11^{\text {th }}$ European Conference on Non-Destructive Testing (ECNDT-14), Prague, Czech Republic

Galietti, U., Palumbo, D., 2016. Data Processing Procedures for Defects Evaluation in Composite Materials by Means of Stimulated Thermography. The e-Journal of Nondestructive Testing, Volume 21(7), pp. 1-9

Ibarra-Castanedo, C., Genest, M., Guibert, S., Piau, J.M., Maldague, X.P.V., Bendada, A., 2007. Inspection of Aerospace Materials by Pulsed Thermography, Lock-in Thermography and Vibrothermography: A comparative study. In: Proceedings SPIE Thermosense XXIX, Bellingham, Washington, USA, Volume 6541, pp. 1-9

Laaidi, N., Belattar, S., 2012. The Numerical Modeling and the Infrared Thermography Principle Applied to the Analysis of Corrosion Defects in Oil Conduits. In: Proceedings of the $11^{\text {th }}$ International Conference on Quantitative Infrared Thermography (QIRT 2012), Naples, Italy

Meng, T., 2008. Detecting Water in Honeycomb of Airbus's Aircraft Elevator in situ by Infrared NDT. In: Proceedings of the $11^{\text {th }}$ Annual Conference on Nondestructive Testing in Shaanxi Province, Hanzhong, pp. 42-46

Oliveira, J.R., Gatti, M.C., Portela, A.M., Tarpani, J.R., 2011. NMRI Study on Water Absorption and Migration in Honeycomb Sandwich Panels. In: Proceedings of the $5^{\text {th }}$ Pan American Conf. for NDT (PANNDT 2011), Cancun, Mexico, pp. 1-3

Protasov, A., 2009. Application of FEMLAB Software for Simulation of the Thermal Method for Nondestructive Testing. In: Proceedings of the Annual Conference and Exposition ASEE, Austin, Texas, USA 
Sánchez-Carballido, S., Justo-María, C., Meléndez, J., Cortés, F., López, F., López del Cerro, F.J., 2013. Experimental Determination of the Thermal Parameters of Carbon FiberComposite Materials Exposed to Fire by Infrared Imaging Pulse Thermography, International Journal of Thermophyics, Volume 34(8-9), pp. 1606-1616

Vavilov, V., Nesteruk, D., 2005. Evaluating Water Content in Aviation Honeycomb Panels by Transient IR Thermography. In: Proceedings SPIE Thermosense XXVII, Bellingham, Washington, USA, Volume 5782, pp. 411-417

Xingwang, G., Feifei, Z., 2012. Study on Pulsed Thermography to Detect Water Ingress in Composite Honeycomb Panels. In: Proceedings of the 11th International Conference on Quantitative Infrared Thermography (QIRT 2012), Naples, Italy

Yu, Y., Shen, G., Qian, J., 2014. Study of Heat Transfering on Composite Cylinder Damage Thermography Inspection. In: Proceedings of the $11^{\text {th }}$ European Conference on NonDestructive Testing (ECNDT-14), Prague, Czech Republic

Zhao, S., Zhang, C., Wu, N., 2011. Pulsed Thermography Detection of Water and Hydraulic Oil Intrusion in the Honeycomb Sandwich Structure Composite. In: Proceedings SPIE International Symposium on Photoelectronic Detection and Imaging 2011: Advances in Infrared Imaging and Applications, Bellingham, Washington, USA, Volume 8193, pp.1-8 